\title{
Role of Midtrimester Localization of the Placenta in predicting Pregnancy Outcome
}

\author{
${ }^{1}$ Shaweez Faizi, ${ }^{2}$ Muralidhar V Pai
}

\section{ABSTRACT}

The localization of the placenta by ultrasound in the second trimester has been hypothesized to have an impact on the pregnancy, in terms of antenatal, intrapartum and postnatal outcome.

Objective: To evaluate the role of placental location in predicting the pregnancy outcome.

Materials and methods: It was a prospective observational study conducted between September 2011 and March 2013 at a tertiary care hospital. Placental location, as determined by midtrimester ultrasound in 620 antenatal women, was divided into five groups - anterior, posterior, fundal, lateral and low lying placenta-depending on where $>75 \%$ of the placental mass was located. Outcome variables, such as antenatal complications, intrapartum events and neonatal outcome in these women were studied.

Results: Out of 620 women, $274(44.1 \%)$ had anterior, 169 (27.2\%) had posterior, $98(15.8 \%)$ had fundal, 61 (9.8\%) had lateral placentae and $18(2.9 \%)$ had placenta previa as per the last scan done at 28 weeks. Pre-eclampsia (27.9\%) and antepartum hemorrhage $(19.7 \%)$ were more common in lateral placenta whereas term prelabor rupture of membranes $(11.2 \%)$ was more common in fundal placenta and these findings were statistically significant. The incidence of intrauterine growth restriction (IUGR) was also found to be higher in patients with lateral (16.4\%) and posteriorly (16\%) implanted placenta although there was no statistically significant association.

Conclusion: Among the various placental sites of implantation, lateral location of the placenta is associated with adverse antenatal outcomes like pre-eclampsia, antepartum hemorrhage and IUGR.

Keywords: Placental location, Ultrasound, Pregnancy outcome. How to cite this article: Faizi S, Pai MV. Role of Midtrimester Localization of the Placenta in predicting Pregnancy Outcome. Int J Infertil Fetal Med 2014;5(3):87-91.

Source of support: Nil

Conflict of interest: None

Date of Received: $28-11-14$

Date of Acceptance: 10-12-14

Date of Publication: September 2014

\footnotetext{
${ }^{1}$ Senior Resident, ${ }^{2}$ Professor

1,2Department of Obstetrics and Gynecology, Kasturba Medical College, Manipal, Karnataka, India
}

Corresponding Author: Muralidhar V Pai, Professor, Department of Obstetrics and Gynecology, Kasturba Medical College, Manipal Karnataka, India, Phone: 08202922379, e-mail: drmvpai@ yahoo.com

\section{INTRODUCTION}

The placenta plays a pivotal role in pregnancy. It reflects the intrauterine milieu and influences the fetomaternal outcome. Proper implantation is quite essential for a healthy gestation. It has been hypothesized that location of the placenta has a bearing on the quality of implantation thereby plays a role on pregnancy outcome. This study was undertaken to find out the correlation between the midtrimester placental location and pregnancy outcome and thus evaluate its role as a predictor such outcome.

\section{MATERIALS AND METHODS}

This prospective observational study was conducted between September 2011 and March 2013, in the department of obstetrics and gynecology, in a tertiary care hospital. The sample size was decided based on estimation of proportion. Prior to enrolment of patients, ethical committee clearance was obtained. Six hundred and ninetysix singleton pregnant women attending the antenatal clinic during the study period were enrolled after taking written informed consent in the language they understood, and were explained the purpose of study. Women with multiple gestation, chronic renal disease, chronic hypertension were excluded.

Baseline demographic information-maternal age, parity and medical history, previous obstetric history were noted using a structured proforma. Complete general physical, systemic and obstetric examination were performed. Gestational age was calculated using last menstrual period when known or using ultrasound dates (as assessed between 8 and 10 weeks).

Transabdominal ultrasound was performed between 14 and 28 weeks of gestation using Toshiba Nimio ultrasound machine with frequency $6.5 \mathrm{MHz}$ transvaginal transducer and $5 \mathrm{MHz}$ transabdominal transducer. Women were followed up to delivery placental location was divided into five groups-anterior, posterior, fundal, lateral and low lying placenta-depending on where $>75 \%$ of the placental mass was located. Placenta previa was defined when the placental edge was located within $2 \mathrm{~cm}$ of the internal os after 28 weeks. ${ }^{1}$

The outcome variables included pre-eclampsia or eclampsia, intrauterine growth restriction (IUGR), 
antepartum hemorrhage, oligohydramnios, preterm prelabor rupture of membranes (PPROM), term prelabor rupture of membranes (TPROM), preterm labor, gestation at delivery, intrauterine fetal demise, duration of third stage of labor, fetal distress in labor (who eventually had cesarean delivery), postpartum hemorrhage and manual removal of placenta (MROP). We also studied neonatal outcomes, such as mean birth weight, Apgar $<7$ at 1 or 5 minutes and early neonatal death.

Statistical package for the social sciences (SPSS-16) was used for statistical compilation and analysis. For statistical analysis of difference between groups, Chi-square test was applied. Statistical significance was accepted at $\mathrm{p}<0.05$.

\section{RESULTS}

A total of 696 women were enrolled for the study, 76 were lost for follow-up. Remaining 620 women were followed up to delivery and analyzed. Out of 620 women, 274 (44.1\%) had anterior, 169 (27.2\%) had posterior, 98 (15.8\%) had fundal, 61 (9.8\%) had lateral placentae and $18(2.9 \%)$ had placenta previa as per the last scan done at 28 weeks and later (Fig. 1).

The mean age, parity, gestational age at scan and the number of women that had cesarean section in the past were matching in all the groups (Table 1). Antenatal complications observed during the study were preeclampsia $(17.58 \%)$, antepartum hemorrhage $(8.06 \%)$, IUGR (14.03\%), PPROM (4.67\%), pre-term labor $(2.41 \%)$, TPROM (6.29\%), malpresentation (6.29\%) and oligohydramnios (12.25\%) (Table 2).

Pre-eclampsia $(27.9 \%)$ and antepartum hemorrhage (19.7\%) were more common when placenta was situated laterally, whereas prelabor rupture of membranes (PROM) was more common in fundal placenta and these findings were statistically significant. The incidence of

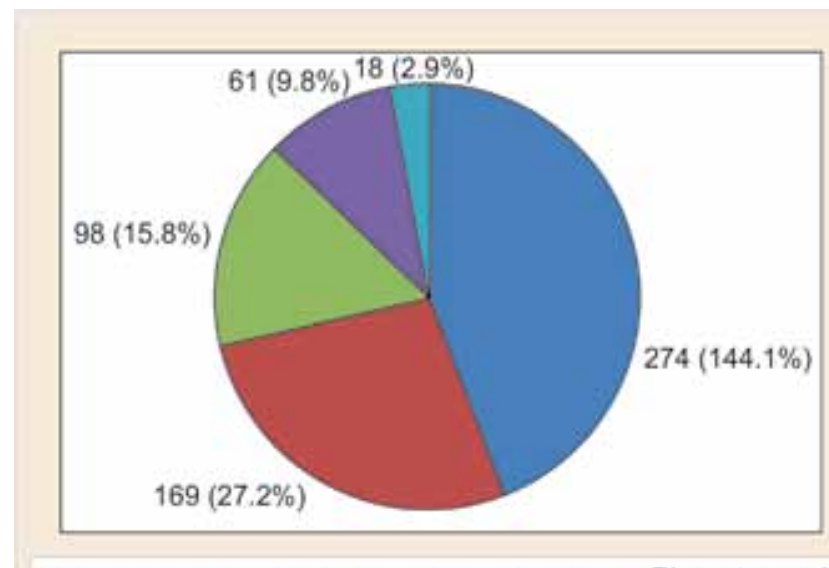

anterior aPosteior aFundal שLateral aPlacenta previa

Fig. 1: Distribution of cases according to placental location $(n=620)$
IUGR was also found to be higher in patients with lateral $(16.4 \%)$ and posteriorly $(16 \%)$ implanted placenta although there was no statistically significant association. Malpresentation (breech or transverse lie) was more common in fundal placenta $(8.2 \%)$ and oligohydramnios was more often seen in anterior placenta (15.3\%), however these findings were statistically not significant (Table 2).

The rate of placental migration was found to be similar for low lying anterior $(81.3 \%)$ and posterior placenta (75.8\%) (Table 3).

A total of 299 cases were allowed vaginal delivery, out of which 124 had fetal distress and hence were taken up for cesarean section and majority (24.6\%) of them had lateral placenta. However, this finding was statistically not significant (Table 4). Among 175 women who had vaginal delivery, the mean duration of third stage of labor was similar in all groups and there was no statistically significant difference. One patient with fundal placenta required manual removal of placenta. A total of $15(8.6 \%)$ patients had postpartum hemorrhage, of which majority $(46.6 \%)$ had anterior placenta. None of these findings were statistically significant (Table 4).

A total of 586 (94.5\%) had live birth and 34 (5.4\%) had still birth. There were four neonatal deaths. There were more stillbirths in women with lateral placentae $(9.8 \%)$ and fundal $(9.2 \%)$, but these findings were statistically not significant (Table 5). Three hundred and ninety-nine (64.3\%) had babies weighing more than $2.5 \mathrm{~kg}, 144(23.2 \%)$ had babies weighing between 1.5 and $2.49 \mathrm{~kg}$, $51(8.2 \%)$ had babies weighing between 1 and $1.49 \mathrm{~kg}$ and $26(4.1 \%)$ had babies weighing less than $1000 \mathrm{gm}$. There was no statistically significant correlation between birth weight and placental location. A total of 107 (17.2\%) babies had Apgar score less than 7 at 1 minute and among them 47 (43.9\%) had persistent low Apgar scores at 5 minutes. Although statistically not significant, low Apgar scores were seen in women with lateral placenta (Table 5).

\section{DISCUSSION}

The purpose of our study was to find out whether the placental location as determined by antenatal ultrasonography has any correlation with pregnancy outcome and hence its role in predicting such outcome.

The blood supply of the uterus is not uniformly distributed. As such, the site of implantation and resultant location of the placenta within the uterus are likely important determinants of placental blood flow and therefore pregnancy success.

In our study, majority (44.1\%) had anterior rather than posterior $(27.2 \%)$ placenta. There was no statistically significant difference in the location of placenta in women with previous cesarean section. In a prospective 
Role of Midtrimester Localization of the Placenta in predicting Pregnancy Outcome

Table 1: Demographic characteristics $(\mathrm{n}=620)$

\begin{tabular}{|c|c|c|c|c|c|c|}
\hline Patient characteristics & $\begin{array}{l}\text { Anterior } \\
(n=274)(\%)\end{array}$ & $\begin{array}{l}\text { Posterior } \\
(n=169)(\%)\end{array}$ & $\begin{array}{l}\text { Fundal } \\
(n=98)(\%)\end{array}$ & $\begin{array}{l}\text { Lateral } \\
(n=61)(\%)\end{array}$ & $\begin{array}{l}\text { Placenta previa } \\
(n=18)(\%)\end{array}$ & $p$-value \\
\hline Mean maternal age at delivery (years) & $27.75 \pm 4.22$ & $27.5 \pm 4.18$ & $27.91 \pm 4.29$ & $26.73 \pm 4.64$ & $28.06 \pm 5.72$ & 0.06 \\
\hline Range (18-42) & $(19-41)$ & $(18-40)$ & $(19-42)$ & $(19-42)$ & $(21-38)$ & \\
\hline Primigravida & $135(44.1)$ & $88(28.8)$ & $44(14.4)$ & $31(10.1)$ & $8(2.6)$ & 0.82 \\
\hline \multicolumn{7}{|l|}{$306(49.4 \%)$} \\
\hline Multigravida & $139(44.3)$ & $81(25.8)$ & $54(17.2)$ & $30(9.6)$ & $10(3.2)$ & \\
\hline \multicolumn{7}{|l|}{$314(50.6 \%)$} \\
\hline Gestational age at latest scan (weeks) & $26.79 \pm 7.55$ & $27.38 \pm 7.10$ & $29.35 \pm 7.23$ & $30.93 \pm 4.78$ & $32 \pm 5.67$ & 0.49 \\
\hline Previous LSCS $(n=145)(23.4)$ & $71(25.9)$ & $37(21.9)$ & $22(22.4)$ & $10(16.4)$ & $5(27.8)$ & 0.54 \\
\hline Total $(n=620)$ & $274(44.2)$ & $169(27.3)$ & $98(15.8)$ & $61(9.8)$ & $18(2.9)$ & - \\
\hline
\end{tabular}

Statistical test: Pearson's chi-square test; p-value <0.05: significant; LSCS: Lower segment cesarean section

Table 2: Correlation of placental location with antenatal complications $(n=620)$

\begin{tabular}{|c|c|c|c|c|c|c|c|c|}
\hline $\begin{array}{l}\text { Antenatal } \\
\text { compli- } \\
\text { cations } \rightarrow\end{array}$ & $\begin{array}{l}\text { Pre- } \\
\text { eclampsia/ } \\
\text { eclampsia } \\
(n=117)(\%)\end{array}$ & $\begin{array}{l}\text { Antepartum } \\
\text { hemorrhage } \\
(n=50)(\%)\end{array}$ & $\begin{array}{l}\text { IUGR* } \\
(n=87)(\%)\end{array}$ & $\begin{array}{l}\text { Preterm } \\
\text { PROM }^{* *} \\
(n=29)(\%)\end{array}$ & $\begin{array}{l}\text { Preterm } \\
\text { labor } \\
(n=15)(\%)\end{array}$ & $\begin{array}{l}P R O M \\
(n=39)(\%)\end{array}$ & $\begin{array}{l}\text { Malpresen- } \\
\text { tations } \\
(n=39) \\
(\%)\end{array}$ & $\begin{array}{l}\text { Oligohy- } \\
\text { dramnios } \\
(n=76) \\
(\%)\end{array}$ \\
\hline Anterior $(n=274)$ & $58(21.2)$ & $22(8)$ & $37(13.5)$ & $16(5.8)$ & $9(3.3)$ & $11(4)$ & $17(6.2)$ & $42(15.3)$ \\
\hline Posterior $(n=169)$ & $26(15.4)$ & $4(2.4)$ & $27(16)$ & $4(2.4)$ & $4(2.4)$ & $16(9.5)$ & $11(6.5)$ & $17(10.1)$ \\
\hline Fundal $(\mathrm{n}=98)$ & $16(16.3)$ & $8(8.2)$ & $13(13.3)$ & $4(4.1)$ & $2(2)$ & $11(11.2)$ & $8(8.2)$ & $11(11.2)$ \\
\hline Lateral $(n=61)$ & $17(27.9)$ & $12(19.7)$ & $10(16.4)$ & $4(6.6)$ & 0 & $1(1.6)$ & $2(3.3)$ & $6(9.8)$ \\
\hline $\begin{array}{l}\text { Placenta previa } \\
(n=18)\end{array}$ & 0 & $4(22.2)$ & 0 & $1(5.6)$ & 0 & 0 & $1(5.6)$ & 0 \\
\hline $\mathrm{p}$-value & 0.016 & 0.001 & 0.42 & 0.48 & 0.57 & 0.014 & 0.82 & 0.91 \\
\hline
\end{tabular}

*IUGR: Intrauterine growth restriction; ${ }^{* *}$ PROM: Prelabor rupture of membranes; Statistical test: Pearson's chi-square test;

p-value $<0.05$ : Significant

observational study by Naji O et al, ${ }^{2}$ it was concluded scar tissue resulting from a cesarean section in the uterus is associated with a higher rate of posteriorly implanted placentae and a lesser incidence of fundal placentae.

The rates of migration studied were comparable among low lying anterior and posterior placenta. In a study done by Jyotsna et al, ${ }^{3}$ it has been noted that placental migration was highest when the initial distance is $>2 \mathrm{~cm}$ between the lower edge of placenta and internal os. However, as few cases in our study did not have the distance between placental edge and internal os measured, we cannot comment upon the same.

In our study, pre-eclampsia was more common (27.9\%) in lateral placenta. This finding was statistically significant. The placenta plays a key role in the pathogenesis of pre-eclampsia. Gonser et $\mathrm{al}^{4}$ analyzed 184 patients between 24 and 36 weeks of gestation correlating the placental location and development of pre-eclampsia. They concluded that women with a lateral placenta had a significantly increased incidence of pre-eclampsia (risk ratio of 3.1), when compared to pregnancies with centrally located placenta. ${ }^{4}$ This is further supported by a recent retrospective analysis by Fung et $\mathrm{al}^{5}$ where a 2.2 and a 2.0 fold higher risk was noted for the development of pre-eclampsia in patients with fundal and lateral placenta than those with a central. Our study also had comparable results to the studies done by Gonser et al and Fung et al. ${ }^{4,5}$ Out of 117 cases of pre-eclampsia, 8 had eclampsia but interestingly none of them had lateral placenta. A prospective observational study by Pillai et $\mathrm{al}^{6}$ was carried out at our hospital between January 2000 to December 2001 where the relationship between the mean uterine artery resistance index and the placental position was noted. When the placenta was unilateral in position, contralateral resistance indices were found to be raised. A unilateral located placenta thus had a 2.7 fold higher incidence of pre-eclampsia. ${ }^{6}$ In the present study also, there is a strong association between placental laterality and development of antenatal complications like pre-eclampsia and antepartum hemorrhage. We found that antepartum hemorrhage was more common in lateral placenta and this finding was also statistically significant. This may be related to the fact that placental abruption is seen more often in pre-eclampsia and, in our study, the incidence of latter was more common in lateral placenta.

Table 3: Correlation of placental location with placental migration

\begin{tabular}{llll}
\hline $\begin{array}{l}\text { Placental } \\
\text { location }\end{array}$ & $\begin{array}{l}\text { Low lying placenta in } \\
\text { midtrimester scan } \\
(n=72)(11.6 \%)\end{array}$ & $\begin{array}{l}\text { Placenta } \\
\text { migrated to } \\
\text { upper segment }\end{array}$ & $\begin{array}{l}\text { Rate of } \\
\text { migration }\end{array}$ \\
\hline Anterior & $43(59.7 \%)$ & 35 & $81.3 \%$ \\
Posterior & $29(40.2 \%)$ & 22 & $75.8 \%$ \\
\hline
\end{tabular}


Table 4: Correlation of placental location with intrapartum events

\begin{tabular}{|c|c|c|c|c|}
\hline $\begin{array}{l}\text { Placental } \\
\text { Iocation } \\
\text { events }\end{array}$ & $\begin{array}{l}\text { Fetal distress in } \\
\text { labor }(n=124)\end{array}$ & $\begin{array}{l}\text { Mean duration of } \\
\text { IIIrd stage of labor (min) }\end{array}$ & $M R O P^{* *}(n=1)(\%)$ & $\begin{array}{l}P P H^{\star * \star}(n=15) \\
(\%)\end{array}$ \\
\hline Anterior $(n=62)$ & $60(21.9)$ & $7.30 \pm 1.15$ & - & $7(46.6 \%)$ \\
\hline Posterior $(n=64)$ & $31(18.3)$ & $6.56 \pm 0.45$ & - & $2(13.3 \%)$ \\
\hline Fundal $(n=98)$ & $18(18.4)$ & $5.58 \pm 0.25$ & 1 & $2(13.3 \%)$ \\
\hline Lateral $(n=61)$ & $15(24.6)$ & $6.16 \pm 1.03$ & - & $2(13.3 \%)$ \\
\hline Placenta previa $(n=0)$ & 0 & 0 & - & - \\
\hline$p$-value ${ }^{*}$ & 0.17 & 0.26 & - & 0.14 \\
\hline
\end{tabular}

*Statistical test: Pearson's chi-square test; p-value <0.05: significant; ${ }^{*} \mathrm{MROP}$ : Manual removal of placenta; ${ }^{* *} \mathrm{PPH}$ : Postpartum hemorrhage

Table 5: Correlation of placental location with perinatal outcome

\begin{tabular}{|c|c|c|c|c|c|c|c|c|c|}
\hline \multirow{2}{*}{$\begin{array}{r}\text { Placental } \\
\text { location }\end{array}$} & \multicolumn{3}{|c|}{ Neonatal outcome } & \multicolumn{2}{|c|}{ Apgar $(<7)$} & \multicolumn{4}{|c|}{ Birth weight $(\mathrm{kg})$} \\
\hline & $\begin{array}{l}\text { Liveborn } \\
(n=586)(\%)\end{array}$ & $\begin{array}{l}\text { Stillborn } \\
(n=34) \\
(\%)\end{array}$ & $\begin{array}{l}\text { Neonatal } \\
\text { death }(n=4) \\
(\%)\end{array}$ & $\begin{array}{l}1 \text { minute } \\
(n=107) \\
(\%)\end{array}$ & $\begin{array}{l}5 \text { minutes } \\
(n=42)(\%)\end{array}$ & $\begin{array}{l}2.5-4 \\
(n=399) \\
(\%)\end{array}$ & $\begin{array}{l}1.5-2.49 \\
(n=144) \\
(\%)\end{array}$ & $\begin{array}{l}1-1.49 \\
(n=51) \\
(\%)\end{array}$ & $\begin{array}{l}<1(n= \\
26)(\%)\end{array}$ \\
\hline $\begin{array}{l}\text { Anterior } \\
(\mathrm{n}=274)\end{array}$ & $264(96.4)$ & $10(3.6)$ & $1(0.4)$ & $49(17.9)$ & $15(5.5)$ & $\begin{array}{l}168 \\
(61.3)\end{array}$ & $75(27.4)$ & $21(7.7)$ & $10(3.6)$ \\
\hline $\begin{array}{l}\text { Posterior } \\
(\mathrm{n}=169)\end{array}$ & $160(94.7)$ & $9(5.3)$ & 0 & $23(13.6)$ & $9(5.4)$ & $115(68)$ & $30(17.8)$ & $15(8.9)$ & $9(5.3)$ \\
\hline $\begin{array}{l}\text { Fundal } \\
(\mathrm{n}=98)\end{array}$ & $89(90.8)$ & $9(9.2)$ & $2(2 \%)$ & $17(17.3)$ & $10(10.3)$ & $63(64.3)$ & $20(20.4)$ & $11(11.2)$ & $4(4.1)$ \\
\hline $\begin{array}{l}\text { Lateral } \\
(\mathrm{n}=61)\end{array}$ & $55(90.2)$ & $6(9.8)$ & $1(1.6 \%)$ & $15(24.6)$ & $7(11.5)$ & $40(65.6)$ & $15(24.6)$ & $3(4.9)$ & $3(4.9)$ \\
\hline $\begin{array}{l}\text { Placenta previa } \\
(\mathrm{n}=18)\end{array}$ & $18(100)$ & 0 & 0 & $3(16.7)$ & $1(5.6)$ & $13(72.2)$ & $4(22.2)$ & $1(5.6)$ & 0 \\
\hline $\begin{array}{l}\text { Anterior } \\
(n=274)\end{array}$ & $264(96.4)$ & $10(3.6)$ & $1(0.4)$ & 49 (17.9) & $15(5.5)$ & 0.67 & & & \\
\hline${ }^{*} p$-value & & 0.10 & & 0.388 & & & & & \\
\hline
\end{tabular}

*Statistical test: Pearson's chi-square test; $p$-value $<0.05$ : significant

Prelabor rupture of membrane was more common in fundal placenta and this finding was statistically significant. The main etiology of PROM is infection and as such there is no direct relationship with the rupture of membrane at term or earlier and location of placenta. Larger observation is needed to find stronger association. There was no statistically significant correlation with occurrence PPROM as well as preterm labor and location of placenta.

Malpresentation (breech or transverse lie) was more common in fundal placenta $(8.2 \%)$. With a fundal placenta, the total length of the uterine ovoid decreases thence predisposing the fetus to occupy a lie that is not longitudinal. Oligohydramnios was more often seen in anterior placenta $(15.3 \%)$. We can not offer any special explanation for this finding. Both the above findings were statistically not significant. In our study, the timing and mode of delivery was based on antenatal fetomaternal complications rather than placental location alone except may be in those who had abruption and placenta previa.
However, this may have been indirectly influenced by the location of placenta whenever the women had severe pre-eclampsia, IUGR, PROM and fetal distress. In fact, out of 299 women who were allowed for vaginal delivery 124 had fetal distress during labor and hence were taken up for cesarean section. Majority (24.6\%) of the women with fetal distress had lateral placenta explaining again placental deficiency in laterally implanted placenta.

In our study, among 175 women that delivered vaginally, the mean duration of third stage of labor was similar in all groups and there was no statistically significant difference. To ensure uniformity in the results, only those cases were selected whose duration of third stage could be measured by the investigator, hence limiting the total number of cases that could be included in the study. One patient with fundal placenta required manual removal of placenta. In the study by Fung et $\mathrm{al}^{5}{ }^{5}$ the incidence of MROP was noted to be more among fundal and lateral placentation in comparison to other sites. The increased need for MROP in fundal placentation may be explained 
by the lack of propagation of sheering. In a fundal placenta, the fundus may be deficient in contractile strength thus hindering sheering action between two cotyledons, thus explaining an increased need for MROP.

A total of $15(8.6 \%)$ patients had postpartum hemorrhage, of whom majority $(46.6 \%)$ had anterior placenta. In cases of anterior placenta previa undergoing cesarean section one may anticipate increased incidence of postpartum hemorrhage due difficulty in suturing friable edges of lower segment. In our study, the incidence of placenta previa was only $2.9 \%$ and they were not exclusively anterior. Out of 620 women, 586 (94.5\%) had live birth and 34 (5.4\%) had stillbirth. There were four neonatal deaths. Being a tertiary care hospital, all cases of stillbirth that were included in the study were cases that were referred to us for further management after intrauterine fetal demise was diagnosed. It was noted that there were more stillbirths in women with lateral placentae (9.8\%) placentae. The still birth in lateral placenta may be attributed to the placental insufficiency. However, these findings were statistically not significant. There was no statistically significant correlation between birth weight and placental location, though most of the IUGR babies belonged to lateral placenta (16.4\%). Kalanithi et $\mathrm{al}^{7}$ performed a retrospective analysis of 796 deliveries but did not find any association of placental location and neonatal birth weight finding.

Although statistically not significant, low Apgar scores were seen in women with lateral placenta tracing the cause of hypoxia to placental insufficiency due to its location. In a study by Magann et $\mathrm{al}^{8}$ it was observed that Apgar of $<7$ was noted at 1 and 5 minutes in patients with lateral implantation of placenta. Low Apgar score ( $<7$ at 5 minutes) in our study however was seen majorly, i.e. 35 of 47 (74.8\%) in preterm deliveries, the rest were contributed to by abruptio placenta in seven cases, eclampsia—two cases and severe IUGR - two cases.

The number of cases in different groups of placental location was not uniform hence in every antenatal or intranatal or neonatal complication it appeared that the incidence of anterior placenta was more. Also some observations were statistically not significant or not in agreement with previous studies. However, when the percentage of given complication in a given group was compared, there was not only statistical significance, the finding could be explained logically also and the findings matched with the earlier studies. For uniformity in observations, such as intrapartum events like duration of third stage of labor, only those cases that were observed by the investigator were included in the study. The mode of delivery was not only determined by the location of placenta but also by other considerations hence some of the intrapartum and perinatal outcomes may not be directly related to placental location and hence could not have stronger statistical significance these are some of the limitations of the study.

\section{CONCLUSION}

Among the various placental sites of implantation, lateral location of the placenta is associated with adverse antenatal outcomes like pre-eclampsia, antepartum hemorrhage and IUGR and may be used to predict these.

\section{REFERENCES}

1. Hull AD, Resnick R. Placenta previa, placenta accreta, abruptio placentae, and vasa previa. Creasy and Resnik's maternal fetal medicine principles and practice. 6th ed. Philadelphia: Saunders/Elsevier; 2009. p.725-737.

2. Naji O, Daemen, Smit A, et al. Does the presence of a cesarean section scar influence the site of placental implantation and subsequent migration in future pregnancies. Ultrasound Obstet Gynecol 2012;40:557-561.

3. ShravageJyotsna C, DhumaleHema A, Bellad MB. Assessment of placental migration in midtrimester low lying placenta. J Obstet Gynecol India 2009;59:317-319.

4. Gonser M, Tillack N, Pfeiffer KH, et al. Placental location and incidence of pre-eclampsia. Ultraschall Med 1996;17:236-238.

5. Fung TY, Sahota DS, Lau T, et al. Placental site in the second trimester of pregnancy and its association with subsequent obstetric outcome. Prenat Diagn 2011;31:548-554.

6. Pillai JR, Pai MV. Role of placental laterality in the prediction of pre-eclampsia 2002.

7. Kalanithi LE, Illuzzi JL, Nossov VB, et al. Intrauterine growth restriction and placental location. J Ultrasound Med 2007;26: 1481-1489.

8. Magann EF, Evans SF, Newnham JP. Placental implantation at 18 weeks and migration throughout pregnancy. South Med J 1998;91:1025-1027. 